\title{
The Issues that Never Die
}

\author{
Daniel Bodansky and Lavanya Rajamani*
}

This article analyses three overarching issues that have bedevilled the climate negotiations right from the start and options for addressing them in the ongoing Paris Agreement Work Programme negotiations. These issues are: (1) How legally binding should the United Nations (UN) climate change regime be? (2) How prescriptive should the UN climate change regime be, and how much should it leave to national discretion? (3) To what extent should the rules of the UN climate change regime be common or differentiated and, if the latter, on what basis and how?

\section{Introduction}

In our recent book, International Climate Change Law (co-authored with Jutta Brunnée), we observed that in the UN Framework Convention on Climate Change (UNFCCC) negotiations, governments 'fought each other to a standstill. They did not resolve issues so much as paper over them either through formulations that preserved the position of all sides, that were deliberately ambiguous, or that deferred issues until later. From this perspective, the adoption of the convention in 1992 represented not an end point, but rather a punctuation mark in an ongoing process of negotiation.'

To what degree can the same be said of the Paris Agreement? After more than a quarter century, has the UN climate regime finally settled on a governance paradigm that allows the negotiations to move into a more technical, less political phase? Or did the Paris Agreement contain enough constructive ambiguity that it allowed each side to live on to fight another day?

Given the nearly universal acclaim with which the Paris Agreement was greeted, it is perhaps understandable that people inferred more agreement in Paris than was actually there. Now, more than two years later, the process of elaborating the Paris 'rulebook' through the Paris Agreement Work Programme has made clear that the same three overarching issues that have beset the United Nations climate regime from the start are still with us:

- How legally binding should the UN climate change regime be?

- How prescriptive should the UN climate change regime be, and how much should it leave to national discretion?

- To what extent should the rules of the UN climate change regime be common or differentiated and, if the latter, on what basis and how ${ }^{2}$
This short article briefly analyses these three issues and how they might be addressed in the Paris Agreement Work Programme negotiations.

\section{The Climate Negotiations Dialectic}

On each of these three issues, the climate regime has followed a similar dialectical development, moving from one end of the policy spectrum to the other, before settling in the Paris Agreement on a hybrid approach somewhere in between:

- On the issue of legal form, the 1997 Kyoto Protocol imposed legally binding targets and timetables on Annex I Parties to limit their greenhouse gas emissions, together with procedural obligations regarding accounting, reporting, and review. The 2009 Copenhagen Accord was its antithesis: a political agreement without any legal force, providing for Parties to submit self-selected national actions and commitments. The 2015 Paris Agreement represents a synthesis: it is a legal instrument establishing a number of procedural obligations; but some of its core elements, including

DOI: $10.21552 / \mathrm{cclr} / 2018 / 3 / 4$

* Daniel Bodansky, Regents' Professor of Law, Sandra Day O'Connor College of Law, Arizona State University, and Lavanya Rajamani, Professor, Centre for Policy Research, New Delhi. For correspondence: <Daniel.Bodansky@asu.edu>. Parts III and IV of this article draws on Daniel Bodansky and Lavanya Rajamani, 'General Issues in Elaborating the Paris Agreement' (Center for Climate and Energy Solutions 2018) < https://www.c2es.org/site/ assets/uploads/2018/04/general-issues-elaborating-paris-rulebook .pdf $>$ accessed 25 August 2018.

1 Daniel Bodansky, Jutta Brunnée and Lavanya Rajamani, International Climate Change Law (Oxford University Press 2017).

2 For a general discussion of these three issues, see ibid. 
Parties' nationally determined contributions (NDCs), do not create legally binding obligations of result.

- On the issue of prescriptiveness, most of the key elements of the Kyoto Protocol were internationally negotiated rather than nationally determined, including, in particular, its emissions limitation targets. The Copenhagen Accord was its antithesis, with virtually no internationally negotiated rules (although the 2010 Cancun Agreements prescribed enhanced transparency procedures). The Paris Agreement represents a hybrid approach, combining nationally determined mitigation contributions with internationally negotiated rules on ambition, progression, and transparency.

- Finally, on the issue of differentiation, the 1995 Berlin Mandate, which initiated the Kyoto Protocol negotiations, explicitly ruled out any new commitments for non-Annex I Parties, and led to the Kyoto Protocol's so-called 'firewall' between Annex I and non-Annex I countries. The 2011 Durban Platform, in contrast, contained no explicit reference to differentiation. The Paris Agreement represents a middle ground, not employing the categorical, annex-based approach of the UN Framework Convention on Climate Change and the Kyoto Protocol, but incorporating tailored differentiation with respect to mitigation expectations, financial commitments, and transparency.

Elements of the Paris Agreement's hybrid approach to legal form, prescriptiveness, and differentiation were present at the creation of the UN climate regime. Like the Paris Agreement, the Framework Convention was a legal agreement with provisions spanning the spectrum of legal character. Like the Paris Agreement, it allowed Parties to nationally determine their mitigation and adaptation policies, but imposed some normative expectations and procedural rules (primarily with respect to reporting). And, like the Paris Agreement, it set forth both common and differentiated obligations. So, in important respects, the

3 Daniel Bodansky, 'The Legal Character of the Paris Agreement' (2016) 25(2) RECIEL 142

4 Lavanya Rajamani, 'The 2015 Paris Agreement: Interplay between Hard, Soft, and Non-Obligations' (2016) 28(2) JEL 337.
Paris Agreement harks back to the original architecture of the Framework Convention.

The question now is whether the Paris Agreement will prove a more stable political equilibrium than the UNFCCC. The UNFCCC was perceived, from the outset, as only the first step in a multi-step process, to be followed by the negotiation of regulatory protocols establishing stronger mitigation commitments. So, while its framework of governance was intended to be durable, its regulatory approach was merely a starting point. The Paris Agreement, by contrast, does not contemplate its own supersession. It is intended to establish a durable regulatory approach that evolves not through the negotiation of new international commitments, but through its cycle of contributions.

\section{The Paris Agreement Work Programme Negotiations}

Although, in Paris, states were able to negotiate delicate compromises on the issues of legal bindingness, prescription, and differentiation - compromises that virtually every state proved willing to accept - the Paris Agreement Work Programme negotiations demonstrate that these compromises were tenuous and did not reflect a broader meeting of the minds. Instead, all three issues have continued to be contentious, as states seek to push the limits of the Paris Agreement's hybrid architecture, take advantage of constructive ambiguity in its provisions, or use the Paris Agreement Work Programme negotiations as an opportunity to renegotiate the agreement itself.

\section{Legal Bindingness}

The degree to which the UN climate change regime should impose legally binding obligations on states has been a central question since the climate negotiations first began more than a quarter century ago. The compromise reached in the Paris Agreement rested on the distinction between the legal form of the instrument as a whole and the legal character of its constituent provisions. ${ }^{3}$ The Paris Agreement itself is a legal instrument - a 'treaty' in the parlance of international law. But its constituent provisions vary widely in their normative force. ${ }^{4}$ On the one 
hand, the agreement establishes a number of new procedural obligations relating to the preparation, communication, accounting, and review of NDCs; ${ }^{5}$ adaptation planning; ${ }^{6}$ and, for developed countries, reporting on support. ${ }^{7}$ On the other hand, the agreement does not make the content of Parties' NDCs legally binding, nor, more generally, does it create new substantive obligations relating to mitigation or finance.

The question in the Paris Agreement Work Programme negotiations is the degree to which the rules, modalities, procedures, and guidelines (MPGs) elaborating the Paris Agreement will themselves be legally binding. In some instances, the Paris Agreement authorizes the Conference of the Parties (COP) serving as Meeting of the Parties to the Paris Agreement (CMA) to adopt legally binding rules by providing that Parties 'shall' act 'in accordance with' relevant CMA decisions. ${ }^{8}$ But whether the CMA chooses to exercise its authority to adopt legally binding rules remains an open question. In drafting decisions, the CMA has considerable latitude to calibrate a rule's bindingness through its choice of verb. For example, it could:

- Make a rule legally binding by providing that Parties 'shall' act in accordance with it.

- Recommend that Parties use a rule, by providing that Parties 'should' follow it.

- Identify a rule but make its use optional, by providing that Parties 'may' follow it.

- Identify a rule and generate an expectation that countries 'will' follow it.

The fact that the Paris Agreement made most of its procedural provisions legally binding and authorised the CMA in discrete instances to adopt legally binding decisions might seem to suggest an expectation that the CMA should do so. But the language of the COP decision that adopted the Paris Agreement illustrates that there was no such agreement in Paris about the legal character of further guidance. Although the decision made its guidance on accounting legally binding by using the verb 'shall', it made its guidance on the information necessary for clarity, transparency, and understanding optional by using the verb 'may'.

The submissions of Parties on the various elements of the Paris Agreement Work Programme illustrate the continuing divergence of views among the Parties on the issue of legal bindingness. In re- solving this issue, the CMA decisions could adopt a common approach, making all of the MPGs hortatory, permissive, or expectational. Or, like the COP decision that adopted the Paris Agreement, the CMA decisions could give different rules different levels of bindingness - for example, the guidance on accounting of NDCs might be mandatory, as authorized by the Paris Agreement, while the guidance on NDC features might be optional. And some Parties suggest that the CMA decisions could impart different levels of bindingness to rules applicable to different groups of Parties. ${ }^{10}$

\section{Prescriptiveness}

As is well known, the Paris Agreement adopted a hybrid approach to prescriptiveness that combines topdown and bottom-up elements. It prescribes a variety of both substantive and procedural rules - for example, that Parties prepare, communicate and maintain NDCs; provide the information necessary for clarity, transparency and understanding when communicating their NDCs; and account for their NDCs. ${ }^{11}$ But, unlike the Kyoto Protocol, the Paris Agreement does not prescribe the content of Parties' NDCs. Instead, it allows Parties to nationally determine the type and stringency of their contributions.

In the Paris Agreement Work Programme negotiations, the Parties are now trying to decide what additional rules to prescribe. In some cases, the Paris

5 Paris Agreement (adopted 12 December 2015, entered into force 4 November 2016) 55 ILM 740 arts 4(2), 4(8), 4(9), 4(13), 13(7), and 13(11).

6 ibid art 7(9).

7 ibid arts 9(5), 9(7), and 13(9).

8 ibid 4(8), 4(13), and 13(13) (the Parties 'shall' do $[\mathrm{x}]$ 'in accordance with' relevant COP decision or guidance).

9 UNFCCC 'Decision 1/CP.21, Adoption of the Paris Agreement' UN Doc FCCC/CP/2015/10/Add.1 (29 January 2016). Compare paras 31 and 32 (Parties 'shall apply' the guidance in para 31 to their second and subsequent NDCs) with para 27 (Parties 'may' include the information identified when communicating their NDCs).

10 See eg, The Bolivarian Republic of Venezuela, 'LMDC Submission on "Modalities, Procedures and Guidelines for the Transparency Framework for Action and Support referred to in Article 13 of the Paris Agreement"' (2017) <http://www4.unfccc.int/sites/ SubmissionPortal/Documents/591 323 131340502613901594 -LMDC\%20submission\%20on\%20Transparency\%20MPGs $\% 20$ Feb\%202017\%20final.pdf> accessed 25 August 2018.

11 Paris Agreement (n 5) arts 4(2), 4(8), and 4(13). 
Agreement authorises but does not require the CMA to prescribe additional rules - for example, regarding the features of NDCs and common time frames ${ }^{12}$ - so on these issues, the threshold question is whether the CMA prescribes any rules at all. On other issues, the Paris Agreement directs the CMA to prescribe rules, modalities, procedures, and guidelines - for example, with respect to the new sustainable development mechanism and the enhanced transparency framework ${ }^{13}$ - so on these issues, the question is how detailed and precise these rules should be. In general, more detailed and precise rules provide greater consistency, predictability, and international discipline, and lend themselves to assessments of compliance or non-compliance. But they require greater agreement and thus are more difficult to negotiate. By contrast, less detailed rules may be simpler to agree and enable the regime to evolve more easily in response to experience and emerging science.

The issues relating to prescription differ for rules that spell out Parties' obligations and for rules elaborating international processes such as technical expert review, the global stocktake, and the compliance and implementation mechanism. For rules that elaborate Parties' obligations, the alternative to international prescription by the CMA is national determination by individual Parties. Consider accounting by Parties of their NDCs. Article 4(13) prescribes a num-

12 ibid arts 4(9) and 4(10).

13 ibid arts 6(7) and Article 13(13).

14 In the case of technical expert reviews, more general rules could be elaborated through meetings among lead reviewers, as has been the practice under the UNFCCC technical expert review process.

15 Contrast for instance, Australian Government, 'Submission on Further Guidance in relation to the Mitigation Section of Decision 1/CP.21' (2017) <http://www4.unfccc.int/sites/SubmissionPortal/ Documents/261_321_131357642219580657-AUSTRALIA-APA \%20Mitigation-Apr-2017.pdf> (suggesting provision of detailed information to accompany NDCs) with Australian Government, 'Submission to the Subsidiary Body for Scientific and Technological Advice on Guidance on Cooperative Approaches referred to in Article 6, paragraph 2 of the Paris Agreement' (2016) <http:// www4.unfccc.int/sites/SubmissionPortal/Documents/261_262 _131219395035622791-Australia\%20UNFCCC\%20Sub \%20Article\%206.2\%20final.pdf> accessed 25 August 2018.On the negotiations relating to Article 6(2), see generally Sandra Greiner and Axel Michaelowa, 'Cooperative Approaches under Art 6.2 of the Paris Agreement: Status of Negotiations - Key Areas of Consensus and Contention' (Perspectives Climate Research and Climate Focus $2018<$ https://climatefocus.com/sites/ default/files/20180301\%20Discussion \%20Paper\%20

-\%20Cooperative $\% 20$ Approaches $\% 20$ consent $\% 20$ and

$\% 20$ dissens\%5B1\%5D.pdf> accessed 25 August 2018. ber of accounting standards that Parties must satisfy. For example, they must account in a manner that promotes environmental integrity and ensures the avoidance of double counting. If the CMA does not adopt any additional accounting guidance, then so long as Parties satisfied the general standards in Article 4(13), they would be free to nationally determine their accounting rules. The question, then, is how far the CMA should limit national discretion through the elaboration of additional accounting guidance. In descending order of prescriptiveness, the CMA could:

- Adopt detailed, precise accounting guidance.

- Identify a number of alternative approaches, among which a Party could choose.

- Prescribe minimum requirements, and allow Parties to nationally determine any additional rules.

- Prescribe general standards that national accounting rules must satisfy (in addition to those already prescribed in Article 13(13)), but allow Parties to develop their own rules.

- Allow Parties to develop their own accounting rules, and simply require them to report on their rules.

- Not adopt any additional accounting guidance at all.

Rules elaborating international processes like technical expert review and the implementation and compliance mechanism also raise a 'who decides?' question. But, here, the alternative to international prescription by the CMA is not national determination, but rather international elaboration by the technical expert review teams themselves or the implementation and compliance committee. The less detailed and precise the rules prescribed by the CMA, the more discretion the technical expert review teams and the implementation and compliance committee will have to resolve issues on their own, either on an ad hoc basis, in the context of individual reviews, or more systematically. $^{14}$

As with the issue of legal bindingness, the various elements of the Paris rulebook could vary in their prescriptiveness. Umbrella Group Parties tend to support more detailed rules elaborating the procedural requirements of the Paris Agreement - for example, on accounting and reporting - but want a lighter touch for Article 6(2) guidance, focusing on the issue of ensuring that internationally transferred mitigation outcomes are not double counted. ${ }^{15}$ Many devel- 
oping countries take the opposite approach, supporting detailed rules on cooperative approaches under Article 6, but a less prescriptive approach on accounting and transparency. ${ }^{16}$ And the European Union generally supports more detailed rules across all of the elements of the Paris Agreement Work Programme. ${ }^{17}$

The process of elaborating rules for different provisions of the Paris Agreement is at different levels of maturity, in part because some areas are more politically fraught than others, in part because there is more experience with some issues than others, and in part because some areas lend themselves to detailed rule-making while others do not. The more detailed and prescriptive the rules are, the more challenging it will be for Parties to reach agreement on them by December 2018. Parties will therefore need to address a set of substantive questions at the intersection of prescriptiveness and timing:

- Which rules, and at what level of prescriptiveness, are critical to the effective operationalization of the Paris Agreement and achievement of its longterm goals, and thus need to be adopted at COP 24 in Katowice?

- Which rules can be left for subsequent elaboration - either because there is not enough known or because there is not enough agreement among states to allow for a detailed rule now?

- Which rules, if less prescriptive at this point in time, could function to enable to exclude the future participation of certain key Parties?

16 Contrast for instance, 'Views of Brazil on the Guidance referred to in Article 6, paragraph 2, of the Paris Agreement' < http://www4 .unfccc.int/sites/SubmissionPortal/Documents/525_262 131198656223045434-BRAZIL\%20-\%20Article\%206.2 $\% 20$ final.pdf $>$ and 'Submission by the Republic of Mali on behalf of the African Group of Negotiators (AGN) on Guidance on Cooperative Approaches referred to in Article 6, paragraph 2 , of the Paris Agreement (Agenda sub-item 10(a))' (2017) <http:// www4.unfccc.int/sites/SubmissionPortal/Documents/586_317 $131350320609564622-S u b m i s s i o n \% 20 b y \% 20$ the\%20Republic $\% 20$ of $\% 20$ Mali\%20on $\% 20$ behalf $\% 20$ of $\% 20$ the $\% 20$ AGN_SBSTA \%2046_Art.\%206.2\%20March\%202017.pdf>, with 'Views of Brazil, Argentina and Uruguay on APA Agenda Item 5: "Modalities, Procedures and Guidelines (MPG) for the Transparency Framework for Action and Support referred to in Article 13 of the Paris Agreement' <http://www4.unfccc.int/sites/SubmissionPortal/ Documents/525 323 131324648255521982-Bra\%20Arg\%20Uy $\% 20-\% 20$ Submission-Art 13\%20Transparency\%20Framework $\% 20$ FINAL.pdf $>$ accessed 26 August 2018, and Venezuela (n 10)

17 See eg 'Submission by the Republic of Malta and the European Commission on behalf of the European Union and its Member States: Submission on Modalities, Procedures and Guidelines for the Transparency Framework for Action and Support referred to

\section{Differentiation}

Perhaps the biggest perceived breakthrough in the Paris Agreement negotiations was on the issue of differentiation. In contrast to the annex-based bifurcation between Annex I and non-Annex I Parties in the Kyoto Protocol, the Paris Agreement reflects a carefully balanced compromise:

- On the one hand, the Paris Agreement's mitigation obligations are generally not differentiated, in contrast to the Kyoto Protocol. Instead, Parties are able to self-differentiate their mitigation efforts through their choice of NDCs.

- In addition, the Paris Agreement does not employ annex-based differentiation, which was central to both the UNFCCC and the Kyoto Protocol.

- On the other hand, the Paris Agreement's provisions on financial assistance continue to be differentiated, along similar lines as the UNFCCC. ${ }^{18}$

- In addition, the Paris Agreement continues to establish different normative expectations for developed and developing countries. For example, developed countries are expected to continue to demonstrate leadership in mitigation by undertaking economy-wide emission reduction targets, while developing countries are only encouraged to move in the direction of economy-wide targets over time. ${ }^{19}$

- The Paris Agreement also provides for differentiation in its transparency framework, but on the basis of developing countries' capacities, rather than for developing countries in general. ${ }^{20}$

in Article 13 of the Paris Agreement' <http://www4.unfccc.int/ sites/SubmissionPortal/Documents/783_323

_131324010340848514-MT-02-23-EU\%20Submission \%20Transparancy\%20APA\%205\%20FINAL.pdf> and 'Submission by the Republic of Malta and the European Commission on behalf of the European Union and its Member States: under Article 6, paragraphs 2, 4 and 8 of Paris Agreement' $<$ http:// www4.unfccc.int/sites/SubmissionPortal/Documents/783_317 _131345685428746919-MT-03-21-EU\%20SBSTA\%2012a\%20b \%20and\%20c\%20EU\%20Submission\%20Article\%206.pdf> accessed 25 August 2018

18 The Paris Agreement's approach to financial commitments differs from that of the UNFCCC in two respects. First, the UNFCCC differentiated its financial commitments on an annex basis, requiring Annex II country Parties to provide assistance, whereas the Paris Agreement differentiates based on the less clear-cut categories of 'developed' and 'developing' countries. Second, the Paris Agreement does not focus only on developed countries; it also encourages other countries to provide financial assistance. See, Paris Agreement (n 5) art 9(2).

19 ibid art 4(4).

20 ibid art 13(2) 
- Finally, the Paris Agreement reiterates the principle of common but differentiated responsibilities and respective capabilities, but appends the language in light of different national circumstances $^{21}$ - an addition that could be interpreted as introducing a more dynamic, flexible approach to differentiation or as merely underscoring the existing dynamism in the terms 'responsibilities' and 'capabilities', which evolve as national circumstances evolve. ${ }^{22}$

Under the pressure of reaching agreement in Paris, all states accepted this non-annex-based, nuanced approach to differentiation. But hopes that Paris had decisively resolved the issue of differentiation have proved unfounded. Instead, differentiation continues to be a central point of contention in the Paris Agreement Work Programme negotiations. The LikeMinded Developing Countries group, in particular, continues to push in some areas for bifurcated, developed-developing country differentiation, on the basis that the Paris Agreement is intended to enhance the implementation of the Convention, which relies on annexes. ${ }^{23}$

Broadly, options regarding differentiation in the Paris rulebook include:

- No differentiation. This is for those authorizations to the CMA that do not explicitly provide for differentiation in the MPGs.

- Differentiation in relation to the provision of support. For example, the CMA could provide scaledup financial resources and targeted capacity-building support to least developed countries (LDCs) and small island developing states (SIDS) to help them implement the rules.

- Differentiation based on type of NDC. For example, the CMA might specify different informational elements or accounting rules for absolute targets, BAU targets, intensity targets, peaking targets, and policies and measures.

21 ibid arts 2(2) and 4(1).

22 See generally Lavanya Rajamani, 'Ambition and Differentiation in the 2015 Paris Agreement: Interpretative Possibilities and Underlying Politics' (2016) 65(2) ICLQ 493; Sandrine Maljean-Dubois, 'The Paris Agreement: A New Step in the Gradual Evolution of Differential Treatment in the Climate Regime?' (2016) 25(2) RECIEL 151; Christina Voigt and Felipe Ferreira, "Dynamic Differentiation": The Principles of CBDR-RC, Progression and Highest Possible Ambition in the Paris Agreement' (2016) 5(2) TEL 285.

23 See eg LMDCs (n 10).

24 Paris Agreement (n 5) art 13(2)
- Differentiation based on differences between Parties. The Paris Agreement's transparency framework reflects this type of differentiation, by giving flexibility to 'those developing countries that need it in light of their capacities'.24 On this basis, the CMA could differentiate a transparency rule for particular categories of Parties such as LDCs or SIDS, which generally need flexibility in light of their capacities, or it could develop agreed measures of capacity (such as gross domestic product per capita).

- Differentiation in relation to timing. Some rules might apply to developing countries generally, or to LDCs and SIDS in particular, at a later point in time that is either self-determined or written into the rules.

- Differentiation that is implicit or self-determined, as for instance in the use of language (such as 'to the extent possible') that gives Parties discretion and flexibility in how they apply the rules.

As with the issue of legal bindingness and prescriptiveness, the various elements of the Paris Agreement Work Programme negotiations could vary in the nature, extent and form of differentiation, as well as the Parties or groups of Parties entitled to avail themselves of differentiation and flexibility. Indeed, even those who continue to support bifurcated, developeddeveloping country differentiation for some issue areas (for instance transparency) are not advocating such categorical differentiation across the board. They accept the more tailored, issue-specific approach to differentiation reflected in the Paris Agreement, rather than a one-size-fits-all approach.

\section{Relationships among the Issues}

Conceptually, the issues of bindingness, prescriptiveness, and differentiation are independent. But, politically, Parties tend to view them together in the context of an overall package. In seeking an agreement in Katowice, Parties will need to decide what tradeoffs to make across the three issues.

Many developing countries, for example, are concerned about the burdens imposed by highly prescriptive, legally binding rules on accounting and reporting; so if others push for such rules, they will likely insist on greater differentiation. Developed states will then need to decide: are they willing to ac- 
cept greater differentiation, if that is the price for stronger rules?

Similarly, many states are likely to see a trade-off between prescriptiveness and bindingness. States that want detailed, binding rules will need to decide: if they cannot get both, which is a higher priority, prescriptiveness or bindingness? Do they prefer a more detailed rule that is non-binding, or a less detailed rule that is binding? Countries that are wary of the potential burdens imposed by binding, detailed rules must then make the same choice: would they prefer detailed but non-binding rules, or binding but less detailed rules?

The Paris Agreement was successful, in large part, because of its carefully calibrated, hybrid solutions to the issues of bindingness, prescriptiveness, and differentiation. Similarly, the success of the Paris Work Programme negotiations will likely depend on the willingness of states to make compromises across these same three issues. Developed countries are unlikely to retreat from the Paris outcome on differentiation by accepting differentiated rules. And developing countries are unlikely to accept detailed, binding rules that are not differentiated. So the likely trade-offs in Katowice will involve the issues of prescriptiveness and bindingness. The Paris rulebook could include detailed rules that are non-binding, and binding rules that are very general. But it is unlikely to include many rules that are both detailed and binding.

Whatever the ultimate outcome, the decisions adopted in Katowice decisions will not finally resolve the issues of bindingness, prescriptiveness, and differentiation. States that do not get everything they want will continue to press their positions. Thus, like its forebears, Katowice will not be the end of the road, but rather a further punctuation mark in the ongoing process of negotiations. 